DOI https://doi.org/10.30525/978-9934-588-79-2-2.36

\title{
A QUESTIONNAIRE TECHNIQUE FOR STUDYING A PASSENGER FUNCTIONAL STATE IN URBAN MASS TRANSPORTATION
}

\author{
Kopytkov D. M. \\ Ph.D. in Pedagogics, Associate Professor, \\ Department of Transport Systems and Logistics \\ O. M. Beketov National University of Urban Economy in Kharkiv
}

Samchuk G. 0.

Ph.D. in Technical Science,

Senior Lecturer at the Department of Transport Systems and Logistics

O. M. Beketov National University of Urban Economy in Kharkiv

Kharkiv, Ukraine

Urban transportation is an integral part of the industrial infrastructure of the city. Its coordinated, stable, and effective operation is a condition for improving the population's life quality and further social and economic development of the urban economy. As it is known, the main task of urban passenger transportation is to bring the passengers to places of employment and study (up to $70 \%$ of the traffic volume). However, by changing the position of the passenger in space, urban transportation, in some way, changes the passenger's functional state. The main consequences of a change of the state are usually a change in the mental, emotional, physical, and behavioral spheres of the passenger as an employee at the main place of work or study. The totality of all the above areas is a human functional state of which the most common are fatigue and stress [1].

The influence of travel duration and conditions on a human mood and well-being, as well as on the functional state, is the subject of transportation research around the world [2-7].

In the comprehensive study [6], the criterion for passenger functional state is labor productivity in the workplace, which is not a universal indicator, for example, for creative workers, since their performance cannot be unambiguously quantified.

Due to this, in the paper [7], the most suitable functional state indicator has been presented, namely the passenger's workplace adaptation time (reflected in the questionnaire below) regardless of the material or nonmaterial production. 
A human state can be determined using objective and subjective research methods [5-8]. Objective methods for studying fatigue include instrumental methods for the main mental processes and the dynamics of the functioning of various physiological systems. As objective signs of fatigue or stress, the indicators of a human working capacity can be used, such as the labor productivity value (decrease the percentage, reject value, number of operational errors) and physiological indicators (brain current value, pulse rate, respiratory rate, signal/irritant response time, etc.). The most common physiological techniques are electroencephalogram (EEG) is an indicator of the brain activation level; electrocardiogram (ECG) is an indicator of the heart muscle activity; electromyogram (EMG) is an indicator of the muscle tone and activity.

The advantage of physiological methods lies in the fact that, firstly, they make it possible to objectively diagnose a human condition, and secondly, they allow quantitatively assessing the disturbances in the functioning of a particular system. The disadvantage of these methods is in using valuable medical equipment, the researcher's special medical education to correctly interpret the results obtained, low technique promptness.

Subjective methods are based on self-observation to obtain information about the current state or response to this state from the respondent [8]. These diagnostic methods involve the use of questionnaires. The advantages of questionnaires include well-developed signs a state (fatigue, stress, etc.), ease of answer, and subsequent answers' processing, high method quickness. The disadvantages are the lack of a quantitative assessment of the state, a person's subjective perception of a state to lead to the resulting inaccuracy.

In psychophysiology and labor psychology [1], the questionnaire techniques are known to measure the performance, concentration, and fatigue during work or study. From the test results, the recommendations should be given, for example, on the workers' professional suitability or the current functional state. Comparing the answers to the tabulated values allows concluding the level of human performance, fatigue and attention concentration.

However, in the case study, their application in a «pure» form can be rather limited, since they demonstrate only the final result and do not disclose the duration of the travel parameters' impact on the passenger, and the perception of these parameters by the passenger depending on transportation mode, age, etc.

Having analyzed the available methods for assessing well-being, psychical and emotional state, mood, and fatigue [5, 8], to fully embrace this 
area a combined approach presented. It is a 2-part questionnaire to reveal the «home-to-work» travel conditions and the subsequent passenger's functional state.

Part 1 of the questionnaire displays the passenger's age, the travel parameters, and the passenger's subjective assessment of the adaptation time if the adaptation took place.

Part 2 of the questionnaire is a table that contains 30 pairs of opposite characteristics to reflect the studied features of the state (well-being, activity and mood). Ten pairs of words represent each state. In the survey form, a rating scale is located between the polar characteristics. The subject is asked to correlate his state with a certain assessment on the scale. When processing the survey results, the grades are recalculated into points from 1 to 7. The quantitative result is the sum of the primary points for individual categories (or their arithmetic mean). The average score of the scale is 4 . Scores exceeding 4 points indicate a good state of the passenger; scores up to 4 indicate the opposite state.

As given in [8], the questionnaire should be used for psychical, mental, and emotional diagnostic examination of workable adults (aged from 18 to 60 - 65 years) without any restrictions on gender, social, professional, and educational grounds. The constructive validity of the technique was established from the comparison with the results of psychical and physiological methods taking into account the indicators of the critical frequency and body temperature dynamics. The current validity was established by comparing the data of the contrast groups, as well as by comparing the results of the subjects at different times of the working day. The methodology developers carried out its standardization from the sample material of 300 people.

An example of a completed questionnaire adopted for the transportation conditions is shown in Figure 1. 


\section{Passenger functional state assessment questionnaire}

Please, complete the form immediately after your "home-to-work" trip in urban mass transportation

Age:

35 years

Transportation Mode:

Wus ПTrolleybus ॠTramway

Total travel time: $\min$.

Nugiber of transfers per travel:

Cabin crowding*:

3 points.

* - I - there are available seats in the cabin; 2 - all the seats are unavailable; 3 - all the seats are unavailable, but the passengers stand freely to in the cabin; 4 - vehicle seating capacity is entirely used; 5 - vehicle is overcrowded. some passengers stayed at the bus stop.

\section{Approximate workplace adaptation time*:}

$10 \mathrm{~min}$.

* - workplace adaptation time is the time needed to accommodate a human body to the production environment: approximate workplace adaptation time can be described by shattering, lack of assimilation, reluctance of performing basic functions, dissipation or attention violation, heaviness or unwillingness in taking any actions, staff communication etc.; please, specify in minutes how long you keep this state after a travel if this state is available.

Please, indicate your partial functional state directly after the urban transportation trip. Values located to the left of 0 mean good (positive) state, values located to the right of 0 mean bad (negative) state

\begin{tabular}{|c|c|c|c|}
\hline $\begin{array}{l}\text { Sign } \\
\text { No. }\end{array}$ & Positive sign & Polar scale & Negative sign \\
\hline 1 & Good well-being & 3010123 & Bad well-being \\
\hline 2 & Feeling of strength & 3200123 & Feeling of weakness \\
\hline 3 & Active & $32(1) 0123$ & Passive \\
\hline 4 & Mobile & 3200123 & Sedentary \\
\hline 5 & Funny & 3210123 & Sad \\
\hline 6 & Good mood & 3200123 & Bad mood \\
\hline 7 & Workable & 3200123 & Broken \\
\hline 8 & Full of strength & 3200123 & Exhausted \\
\hline 9 & Fast & 3210123 & Slow \\
\hline 10 & Active & 3200123 & Inactive \\
\hline 11 & Happy & 3210123 & Unhappy \\
\hline 12 & Cheerful & 3200123 & Gloomy \\
\hline 13 & Relaxed & 3210023 & Tense \\
\hline 14 & Healthy & 3200123 & III \\
\hline 15 & Indifferent & 3200123 & Enthusiastic \\
\hline 16 & Apathetic & 3210123 & Excited \\
\hline 17 & Rapturous & 3200123 & Despondent \\
\hline 18 & Glad & 3200123 & Sad \\
\hline 19 & Rested & 3210023 & Tired \\
\hline 20 & Fresh & 3200123 & Worn-out \\
\hline 21 & Vivacious & 3200123 & Sleepy \\
\hline 22 & Desire to work & $3(2) 10123$ & Desire to rest \\
\hline 23 & Calm & 3200123 & Anxious \\
\hline 24 & Optimistic & 3010123 & Pessimistic \\
\hline 25 & Robust & 3210123 & Weary \\
\hline 26 & Bouncy & 3200123 & Sluggish \\
\hline 27 & Easy thinking & 3200123 & Hard thinking \\
\hline 28 & Attentive & 3200123 & Scattered \\
\hline 29 & Hopeful & 3010123 & Disappointed \\
\hline 30 & Satisfied & 3200123 & Unsatisfied \\
\hline
\end{tabular}

Fig. 1. Completed questionnaire to survey the passenger functional state 
As can be seen from the questionnaire data, the functional state of the respondent is good, since the average score is 4.7 , and the workplace adaptation time indicated is relatively low.

Despite the declared universality and questionnaire consistent result in the case study, it cannot be accepted as a conclusive and reliable one. The questionnaire requires to be checked for contradictions by methods of mathematical statistics, which is a validity check for results in urban transportation conditions, finding the correlation density between its parameters (for example, «average score-to-adaptation time», «adaptation time-to-age» etc).

\section{References:}

1. Леонова А.Б., Кузнецова А.С. Функциональные состояния и работоспособность человека в профессиональной деятельности. В кн : Психология труда, инженерная психология и эргономика. Москва, 2015. $619 \mathrm{c}$.

2. Jing Zh., Yingling F. Daily travel behavior and emotional wellbeing: Effects of trip mode, duration, purpose, and companionship. Transportation Research. Part A. 2018. No. 118. P. 360-373.

3. De Vos J., Schwanen T., Van Acker V., Witlox F. Travel and subjective well-being: a focus on findings, methods and future research needs. Transport Reviews. 2013. No. 33 (4). P. 421-442.

4. Morris E.A., Guerra E. Are we there yet? Trip duration and mood during travel. Transportation Research. Part F: Traffic Psychology and Behaviour. 2015. Vol. 33. P. 38-47.

5. Friman M., Fujii S., Ettema D., Gärling T., Olsson L.E. Psychometric analysis of the satisfaction with travel scale. Transportation Research. Part A. 2013. No. 48. P. 132-145.

6. Доля В.К. Пасажирські перевезення. Харків. 2011. 504 с.

7. Kopytkov D., Levchenko O., Rossolov A., Samchuk G. Determination of the passenger transport fatigue in urban mass transportation. Municipal Economy of Cities. 2018. No. 7 (146). P. 2-11.

8. Барканова О.В. Методики диагностики психоэмоциональной сферы. Красноярск. 2009. 237 с. 